\title{
Incidence of Emerging and Innovative Climate Change Adaptation Practices for Smallholder Farmers' in Nachingwea District, Southern Tanzania
}

\author{
Josephat Alexander Saria \\ Faculty of Science, Technology and Environmental Studies, the Open University of Tanzania, Dar es Salaam, Tanzania
}

\section{Email address:}

josephat.saria@out.ac.tz

\section{To cite this article:}

Josephat Alexander Saria. Incidence of Emerging and Innovative Climate Change Adaptation Practices for Smallholder Farmers' in Nachingwea District, Southern Tanzania. International Journal of Environmental Monitoring and Analysis. Vol. 3, No. 5, 2015 , pp. $304-311$. doi: 10.11648/j.ijema.20150305.20

\begin{abstract}
In view of the spatial hierarchical order of factors influencing farmers' decision making on climate change adaptation we should note that adaptation occurs at two main levels; farm level that focuses on micro-level analysis of farmer decision making and national, or macro-level factors that are concerned about agricultural production at the national and regional scales. The purpose of this paper is to understand the factors determining smallholder farmers' adaptation strategies to climate change, in Nachingwea district and toward sustainable management of their agricultural production and livelihood. Both primary and secondary data were used. Primary data were collected by use of structured questionnaires, key informant interviews and focus group discussions. Based on the research plan, a total of 250 individual households were randomly selected and interviewed. About $92 \%$ of smallholder farmers in the study area indicated climate change is really happening. To smallholder farmers the concept "climate change" was associated with variability in weather conditions such as rainfall inconsistency and unpredictability over years. At the community level the effects of climate change and variability were revealed through food shortages as reported by $52.8 \%$ of the respondents, infestation of uncommon pests $(53.5 \%)$, too much rainfall (43.2\%), diminishing rainfall/drought (64.6\%) and human diseases $(32.5 \%)$. The findings of this study have important policy implications for the promotion of climate change adaptation strategies at the farm level in semi-arid regions, coastal area and elsewhere. To facilitate farmer's investment in long-term adaptation options, government should ensure that tenure arrangements, even in communal smallholder farming system in the country, are secured.
\end{abstract}

Keywords: Adaptation, Climate Change, Perception, Smallholder Farmers, Nachingwea

\section{Introduction}

Although both they are used interchangeably, there are surprisingly few published definitions of either "subsistence peasant" or "smallholder/small scale farmers." The subsistence peasants are people who grow what they eat, build their own houses, and live without regularly making purchases in the marketplace [1, 2]. However, despite the primacy of self-sufficiency in subsistence farming, today most subsistence farmers also participate in trade to some degree, though usually it is for goods that are not necessary for survival, and may include sugar, iron roofing sheets, bicycles, used clothing, and so forth. Most subsistence farmers today reside in developing countries where Tanzania is not exceptional. Although their amount of trade as measured in cash is less than that of consumers in countries with modern complex markets, many have important trade contacts and trade items that they can produce because of their special skills or special access to resources valued in the marketplace [3].

Smallholder/small scale farmers is used more generally to describe rural producers, predominantly in developing countries, who farm using mainly family labor and for whom the farm provides the principal source of income [4]. "Smallholder and subsistence farmers" is used here to denote these farmers, who can be found on a continuum between subsistence production and concentration on crop production for the market. Definitions by scale are relative to national contexts, and "smallholders" in transitional or developed countries may have farms (and incomes) many times larger than those in developing countries. 


\subsection{Agriculture Sector in Tanzania}

Agriculture is a dominant sector of the Tanzanian economy, generating $25 \%$ of GDP, $24 \%$ of exports, and is the mainstay of $75-80 \%$ of livelihoods in the country including the majority of the poor [5]. It is a sector of contrasts: despite having a relatively rich base of land and water resources and a favorable climate in many areas for the majority of years, it is hampered by low productivity and persistent poverty. Crop diversity is high, but the majority of households engaged in the sector grow a limited number of food crops for subsistence, and despite the resource endowments these households are vulnerable to food security and economic shocks. Notwithstanding growth in the Tanzanian economy and in the agriculture sector, little has translated to the poor, who still depend on rudimentary technologies and uncertain rainfall for their livelihood and food security. These factors influence the impact climate variability and climate change will have on the agriculture sector, as well as the capacity to adapt to current and changing conditions.

Agriculture is a dominant sector of the Tanzanian economy, generating $25 \%$ of GDP, $24 \%$ of exports, and the mainstay of $75-80 \%$ of livelihoods in the country including the majority of the poor [5]. Yet growth is slow compared to other sectors, with the share of GDP falling from $29 \%$ to $23 \%$ between 2000 and 2012. Sector GDP has grown but at a slower rate than the economy as whole, $4.4 \%$ compared to $7 \%$ [6]. This is also low compared to a $2.4 \%$ rural population growth rate [7-10]. Most growth of the sector has concentrated on larger-scale production of rice and wheat, and export crops (cotton, sugarcane, tobacco) in the country's northern and eastern areas. Taken together, these trends indicate linkages between modest sector performance and the persistence of rural poverty. The slow pace of agricultural growth relative to other sectors stems from a range of factors, including weaknesses and low capacity along the entire supply chain, vulnerability to climate shocks, and poor infrastructure [8].

\subsection{Status of Food Security in Tanzania}

Food security is a complex condition. Its dimensions availability, access, utilization and stability are better understood when presented through a suite of indicators. Food availability plays a prominent role in food security. Supplying enough food to a given population is a necessary, albeit not a sufficient; condition to ensure that people have adequate access to food. Over the last two decades, food supplies have grown faster than the population in developing countries, resulting in rising food availability per person.

Africa remains the region with the highest prevalence of undernourishment, with around one in four people estimated to be undernourished [11]. While sub-Saharan Africa has the highest prevalence of under nourishment, there has been some improvement over the last two decades, with the prevalence of under nourishment declining from 32.7 percent to 24.8 percent [11].

In Tanzania, agricultural system is largely rain dependent and highly vulnerable to climatic fluctuations (the norm since
1996), especially the semi arid and arid areas of central and northern Tanzania. Pitiable access to water and declining soil fertility are the main limiting factors to agricultural production. A large part of the country is considered semi arid. Weather patterns have of recent deviated greatly from traditional seasons, and remain to the best part unpredictable. Irrigated land makes up only $4.3 \%$ of the total area. Nevertheless, agriculture accounts for $89 \%$ of water used in the country, and contributes not less than $50 \%$ of the GDP [6]. Eighty percent of the agricultural production in Tanzania is undertaken by small farmers using simple basic technology [10].

Food insecurity in Tanzania has increased over the recent decade. Number of undernourished people has also increased from $23 \%$ to $40 \%$ in the past decade, with the average daily per capita calorie supply at 2,054 against the world average of 2,709 [10]. Severe underweight afflicts nearly $27 \%$ of the under five children, with $42 \%$ being under their rightful height Production of staples in the northern regions of Tanzania has been largely below average, with maize production being $69 \%$ under expectations. Cereal production in 1998 was at 3.8 million tonnes (e.g., 0.14 kilogrammes per capita), and the average yield per hectare was 1.21 tonnes. Yields have declined by $6.7 \%$ in the past ten years [6].

\subsection{Climate Change Effect on Agriculture System and How Smallholder Farmers Dealt with}

It is widely noted that climatic systems around the world are experiencing several changes [12]. Notably, most of these changes have been found to affect temperature and precipitation patterns [13]. These affected weather patterns are of paramount importance for agricultural production. Thus, the agricultural sector is very likely to be adversely affected by such changes. For instance, it is expected that with such changes, cereal production in developing countries will decrease by $9 \%$ [9]. In addition, the changes and resulting consequences could increase the number of people at risk of hunger by up to 600 million by 2080, especially in Africa [9]. Likewise, with intensified hydrological cycle, extreme weather events such as floods and droughts are expected to become much more severe and frequent over the next century in most parts of the world [9].

Climate change is also expected to alter pest and disease outbreaks, increase the frequency and severity of droughts and floods, and increase the likelihood of poor yields, crop failure and livestock mortality [14]. As many of the countries that will be the hardest hit by climate change are tropical countries with large populations of poor, smallholder farmers there is an urgent need for the global community to focus its attention on identifying adaptation measures that can help these farmers reduce their vulnerability to climate change and cope with adverse consequences [15].

Agriculture in developing countries like Tanzania must undergo a significant transformation in order to meet the related challenges of achieving food security and responding to climate change, which is highly variable and complex, and climate trends already indicate that temperatures are rising and rainfall is becoming more erratic [5]. Projections based on 
population growth and food consumption patterns indicate that agricultural production will need to increase by at least 70 percent to meet demands by 2050 [5]. Most estimates also indicate that climate change is likely to reduce agricultural productivity, production stability and incomes in some areas that already have high levels of food insecurity. This is due to weather-related risks already impacting the agriculture sector, and without urgent adaptation the impacts are likely to increase with rising climate variability.

Smallholder farmers in Tanzania are under threat from climate change impacts as they inhabit areas that are highly dependent on farming systems which are sensitive to the already volatile climate. In addition to the policy makers' effort to enhance food security under the changing climate, climate smart agriculture (CSA) has also being thought of as a promising breakthrough for responding to climate change impacts in Tanzania. CSA strives to attain three main goals, which are increasing food productivity; building resilience of agricultural systems to climate change impacts and reducing agricultural greenhouse gas emission through promoting efficient use of land, water, soil and other environmental resources. Developing an appropriate and feasible climate-smart and climate-resilient agriculture practices are perceived to reduce hunger and improve food security and income [16]. Transforming existing agriculture systems into climate-smart agricultural systems can negate the impacts of climate change. It is necessary in order to address these emerging and unavoidable challenges [16]. The important option is to build sustainable food systems, improve productivity and income of smallholder farmers. Climate-smart Agriculture interventions are location specific, and to a large extent their adoption needs to be well-suited to users in terms of willingness, ability to practice, knowledge and their investment capacity [17].

This study examines the smallholder farmers' perception of climate change impacts and their preference on climate smart agricultural practices in the breadbasket areas of the Southern Region of Tanzania.Through the study of local perception of the climate change, local practices and potential implication of adoption of CSA on agricultural production among smallholder farmers.

\section{Methodology}

\subsection{Description of the Southern Tanzania, Nachingwea District}

The 2012 census gave the Nachingwea District population as 178,464 , with an average household size of 3.7 . The district ranging in size from around 3000 to over 16,000 people.Based on altitude, rainfall pattern, dependable growing seasons and average water holding capacity of the soils and physiographic features, Tanzania has 7 main agro-ecological zones. These are the coast, arid lands, semi-arid lands, the plateaux, Southern and Western highlands, Northern Highlands and Alluvial plains [18].

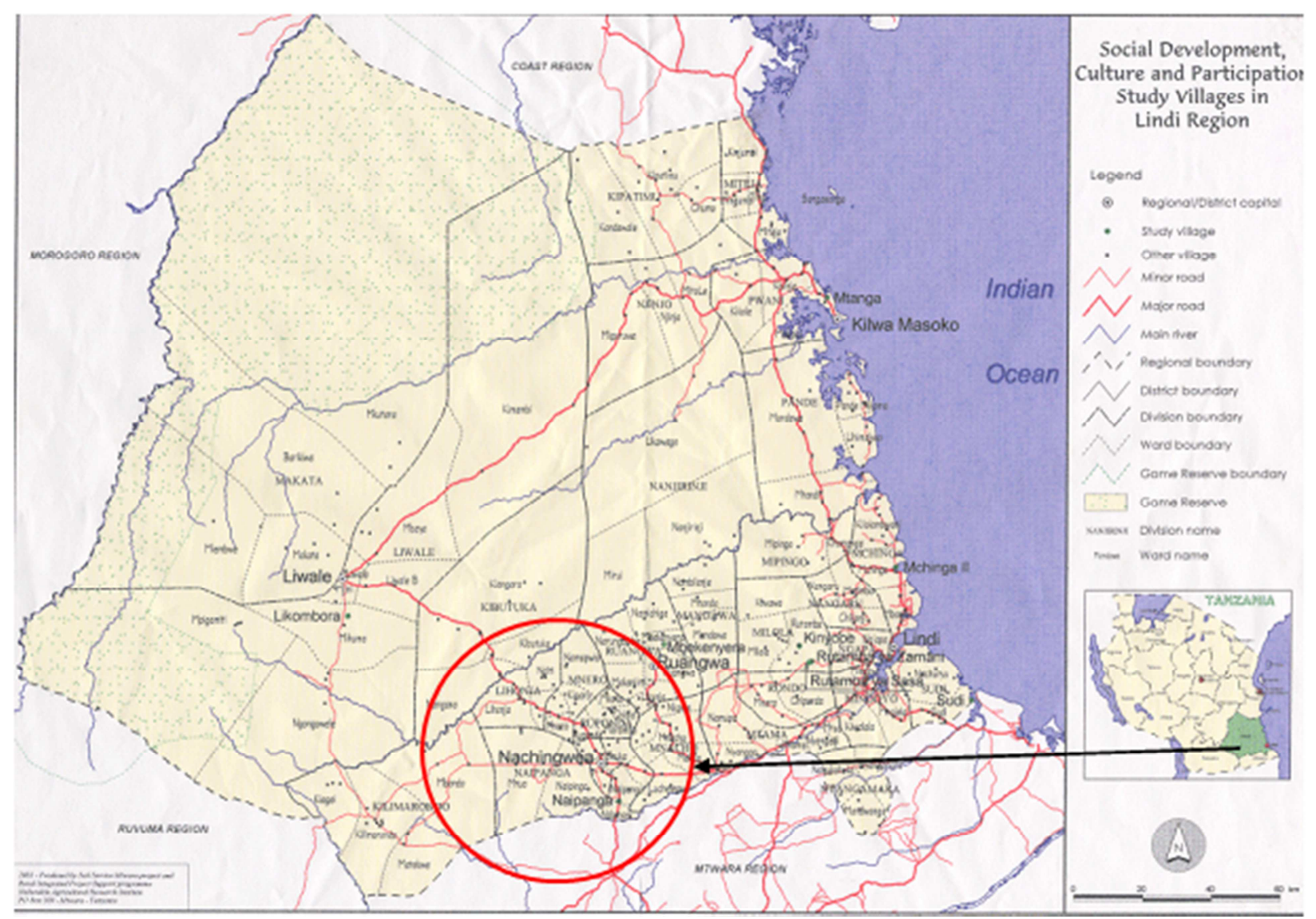

Figure 1. Map of the Tanzania Showing Nachingwea District the Study Areas [18]. 
The study was conducted at Nachingwea District in Lindi Region. Nachingwea is one of the six districts in Lindi region. The district borders with Ruangwa district in the North-East, Masasi district to the south-east, Tunduru district to the South-West, and Liwale district to North-West. Administratively, the district has five (5) divisions, which in turn are sub divided into 27 wards and a total of 104 villages with 41,580 households. The district has a population of 161,473 people of which 78,494 were males and 82,979 were females [19]. The main ethnic groups are Mwera, Ngido, Yao, Makonde and Makua.

The district experiences tropical climate where the warmest month of the year is December with an average temperature of $27^{\circ} \mathrm{C}$ while in July the average temperature is $21.9^{\circ} \mathrm{C}$ in which it is the lowest average temperature of the whole year, the average variation of temperature during the whole year is $5.1^{\circ} \mathrm{C}$. Driest month is August with $4 \mathrm{~mm}$ of precipitation while most precipitation falls in January with an average of $180 \mathrm{~mm}$. Their main peoples activity is Agriculture, major crops grown in the district include cassava, sorghum, legumes, maize, cashew, millet, sesame, bambara-nuts and groundnuts, paddy fruits and Irish potatoes; few of them practice small scale livestock keeping.

\subsection{Population and Sampling Procedures}

Multistage sampling technique was used to select, two hundred andfifty (250) respondents (Smallholder farmers) for the study from five different wards (Nambambo, Ruponda, Lionja, Naipanga and Mbondo). A common motivation for cluster sampling was to reduce the average cost per interview. Given the nature of the study, it was envisaged that most of the variation in the population is within the groups, not between them. This was important to assure the accuracy of the ensuing results. Structured interview schedule was administered on respondents through personal contact also open handed and closed questionnaires was used so as to obtain information on the climate changes perception and their induced risks from respondents.

The field work for the study was conducted from April 2014 to September 2014, for collection of necessary information in three main stages involving interviews with key informants, focus group discussion with farmers and a household questionnaire survey. The main tools for data collection were review of relevant literature, household survey with a structured questionnaire, semi-structured interviews with key informants within the selected project areas. Other tools included focus group discussions and field observations. In each study ward one FGD meeting based on gender, age and socio-economic representation were carried out. Data analysis was carried out using the Statistical Package for Social Sciences (SPSS version 16.0) as well as content analysis for qualitative data.

\section{Results and Discussion}

\subsection{Community Awareness on Climate Change}

The study revealed that $(92.4 \%)$ of small holder farmers already noted that climate change is really happening. The concept "climate change" was associated with variability in weather conditions such as rainfall inconsistency and unpredictability over years. However, people in the studied areas were not able to define climate change and adaptation strategies as used in their fields. When they were interviewed on the source of information about climate change about $30 \%$ of farmers indicated it is from their own observations while only $6.4 \%$ indicated it is from different village meetings (Figure 2).

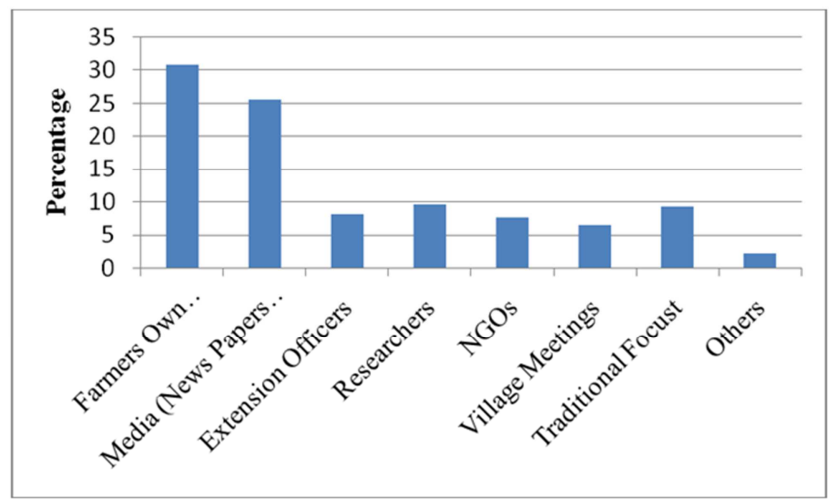

Figure 2. Source of Knowledge about Climate Change.

It was however worth assessing the level of climate change knowledge based on gender perspective since men and women may perceive climate change differently. This has huge bearing on the decision about and implementation of local coping strategies. While the large number of male respondents (63\%) from studied areas had knowledge on climate change, only $37 \%$ of female respondents were found with that knowledge (Figure 3). This means that although women are the most vulnerable, they are the ones with little knowledge on climate change.

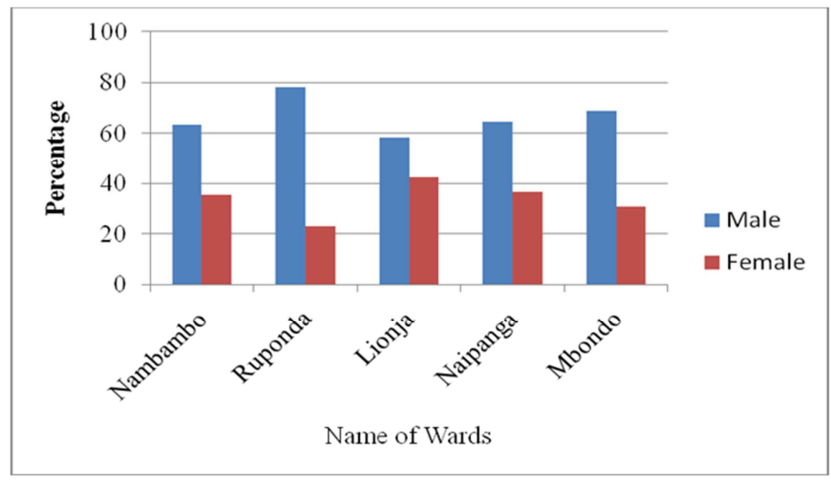

Figure 3. Gender Knowledge about Climate Change.

The degree to which people are affected by climate change impacts is partly a function of their social status, gender, poverty, power and access to and control over resources [20]. The international community acknowledges that women and men have different experiences and skills in coping with climate change impacts, contributed by the fact that women have little economic, political and legal influence and are thus less able to cope with, and are more exposed to the adverse 
effects of the changing climate. Women in developing countries are particularly vulnerable to climate change because they are highly dependent on local natural resources for their livelihood [20]. Women are also charged with securing water, food and fuel for cooking and heating. Women also experience unequal access to resources and decision-making processes, with limited mobility in rural areas. These results, coupled with the findings of this study suggest that it is important to identify gender-sensitive strategies that respond to these crises for women [20].

\subsection{Farmers' Perception About the Causes of Climate Change}

Findings from the survey revealed that farmers perceive differently on what are the main agents of climate variability. Figure 4 shows that $46.5 \%$ of respondents were aware that the main agents of climate change are human activities and deforestation while $21.2 \%$ of perceived that the changes in climate were due to over population lead to constructions. Other issues like scientific experiments (3.3\%) and punishment from God due to increase of evils $(2.1 \%)$ were also considered and key source of climate change.

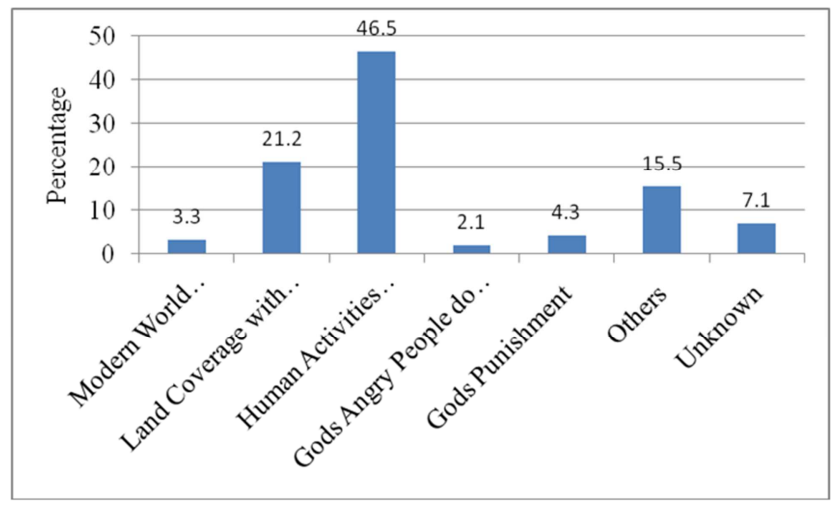

Figure 4. Farmers Perception about the Main Agents of Climate Change.

These results imply that more than $60 \%$ of the people in the study area were unaware that the main agents of climate change were the human beings due to their day to day economic activities. Human beings are therefore compelled to clear forests so as to expand their farms, cut down trees for shelter and many other unfriendly practices to the environment.

\subsection{Indicators of Climate Changing}

The study has revealed that there is a growing perception among the villagers that climate change and variability is already occurring. At the ward level, the concept "climate change" was associated with variability in weather conditions which is related to rainfall inconsistency and unpredictability over years rather than actual change. The variability was related to variations in agricultural seasons in a year.

Major concerns were related to indicators like reduced amounts of rainfall, rainfall coming late, increased temperatures, increased incidences of drought and decreased crop productivity (Table 1).

Table 1. Local Indicators on Climate Change.

\begin{tabular}{|c|c|c|c|c|c|}
\hline \multirow{2}{*}{$\begin{array}{l}\text { Local Indicator } \\
\text { of Climate } \\
\text { Change } \\
\end{array}$} & \multicolumn{5}{|c|}{ Percentage $N=20$ per Ward } \\
\hline & Nambambo & Ruponda & Lionja & Naipanga & Mbondo \\
\hline Late rainfall & 73.2 & 72.8 & 56.4 & 64.8 & 77.9 \\
\hline $\begin{array}{l}\text { Decreased crop } \\
\text { productivity }\end{array}$ & 58.8 & 65.4 & 73.5 & 62.0 & 52.7 \\
\hline $\begin{array}{l}\text { Outbreak of } \\
\text { plant and animal } \\
\text { diseases }\end{array}$ & 66.6 & 48.8 & 61.9 & 63.2 & 62.2 \\
\hline $\begin{array}{l}\text { Shortened } \\
\text { growing seasons }\end{array}$ & 32.8 & 43.2 & 24.0 & 42.7 & 12.8 \\
\hline $\begin{array}{l}\text { Increased crop } \\
\text { pests }\end{array}$ & 48.2 & 53.5 & 34.7 & 40.0 & 27.9 \\
\hline $\begin{array}{l}\text { Amount of } \\
\text { rainfall decrease } \\
\text { each year }\end{array}$ & 95.2 & 67.4 & 88.5 & 76.5 & 90.7 \\
\hline $\begin{array}{l}\text { Increase in } \\
\text { temperature }\end{array}$ & 73.5 & 66.7 & 45.1 & 73.4 & 56.8 \\
\hline $\begin{array}{l}\text { Outbreak of } \\
\text { human diseases }\end{array}$ & 32.5 & 23.3 & 13.6 & 31.8 & 24.7 \\
\hline $\begin{array}{l}\text { Re-occurrence } \\
\text { of food shortage }\end{array}$ & 43.7 & 52.8 & 14.3 & 37.9 & 48.0 \\
\hline $\begin{array}{l}\text { Drought } \\
\text { increases }\end{array}$ & 64.6 & 53.5 & 58.5 & 48.2 & 49.4 \\
\hline $\begin{array}{l}\text { Heavy and } \\
\text { unpredictable } \\
\text { rain }\end{array}$ & 35.6 & 24.1 & 43.2 & 32.9 & 27.8 \\
\hline
\end{tabular}

At the ward level, climate change was associated with variability in weather conditions which is associated with rainfall inconsistency and unpredictability over years, rather than changes themselves. The variability was related to variations in agricultural seasons in a year. Major concerns were related to indicators like reduced amounts of rainfall, late onset and early withdrawal of rainfall seasons, increasing surface temperatures, and increased incidences of dry (Table 1). In most cases, floods as an indicator of climate change fetched very little score as compared to other indicators. This is truly relevant because the highly ranked outcry in as far as climate change is concerned dwelled on diminishing rainfall amount, and thus it is logical not to find floods cropping up as one of the most nagging climate issues in the study areas. In another study they also found out that increasing temperatures; shortened growing seasons; late coming of rains in the seasons, recurrent food shortage, rainfall coming too early in the seasons, and increased incidences of drought emerged as the major indicators of climate change [21].

At the community level the effects of climate change and variability were revealed through food shortages as reported by $52.8 \%$ of the respondents, infestation of uncommon pests $(53.5 \%)$, too much rainfall $(43.2 \%)$, diminishing rainfall/drought (64.6\%) and human diseases (32.5\%). According to discussions with key informants, climate change and variability resulted in lower crop production, decreased land productivity and increased production cost. 


\subsection{Impact of Climate Change on Food Security}

The evaluation of the impact of climate change on food security was undertaken by looking at various aspects of food security. This included identification of main staple foods in different locations, and the actual meaning of food shortage. This further included an assessment of experience of food shortages and associated causes, and finally how households dealt with food shortage.

\subsection{Main Staple Foods}

Maize was found to be the main staple food in all villages followed by soghum. Apart from maize and beans, most respondents in Nambambo and Mbondo wards also mentioned rice as another staple food. In Naipanga, Ruponda and Lionja soya beans and cassava also featured as staple food. These results indicate specialization of respondents in only few staple foods, which has implications in relation to food security, particularly in case of failure of the major staples in a specific area.

Regarding the experiences of food shortages in a normal year, the results indicate that the majority of respondents $(65 \%)$ did experience food shortage throughout the season in a normal year. However, a considerable proportion (35\%) reported to experience some food shortages especially from December to February. These findings entail that rural communities are not homogenous. Even in what is regarded as food insecure villages, there are households which can be secured throughout the year. This study in inline with findings by another researcher [22] in his study at Kasulu, Kigoma district found out that an average of $68 \%$ of the sampled households reported to experience food insecurity sometimes in a normal year. In case of abnormal years (e.g., drought) this study established that majority of households do experience food shortages. The findings further show that in the past years, food stocks could last longer because rains were adequate compared to recent years in which droughts are common. This implies that the droughts in recent years have pronounced effects in crop production as compared to the past.

However, main causes of food shortages appear to be those related to socio-economic factors such as high price of inputs, low productivity and selling food to meet other needs. The most mentioned natural factors include drought, bad weather conditions and unreliable rainfall. Other significant causes included crop diseases, crop pests, low soil fertility, and lack of/low harvests. Increased incidence of crop pests and diseases are expected due to higher temperatures and rainfall. This has led to farmers using more agrochemicals and disease resistant varieties, thus increasing production costs [23-26]. More given reasons included: poor health that affects labour power, lack of agricultural inputs, small farm sizes, destructive birds and use of local varieties.

\subsection{Local Coping and Adaptive Strategies Climate Change Impacts}

Households were found to have variety of ways to deal with food shortages (Table 2). These measures included aspects such as buying food, getting assistance from relatives, selling livestock to buy food, work for food, reducing amount of daily meals, eating unusual foods, borrowing food, getting relief food, reducing number of meals and migrating to other areas. From Table 2 it appears that buying food (37\%) is the prominent way of dealing with food shortage which implies a need for income generating activities to provide the required cash. It was also revealed that some farmers grow crops and fruit trees around their vicinity as an adaptation measure to food shortage.

Table 2. Household Mechanisms for Dealing with Food Shortages $N=250$.

\begin{tabular}{ll}
\hline & Percentage of respondents \\
\hline Work for cash & 2 \\
Use of seeds resistant to drought & 15 \\
Selling livestock like cow and goats for food & 5 \\
Doing work for food & 18 \\
Rely on assistance from relatives & 9 \\
Reducing amount of food eaten & 7 \\
Buying food from market places & 37 \\
Getting relief food from those having stocks & 4 \\
Eating unusual food & 12 \\
Borrowing food from friends & 7 \\
Reducing number of meals even once a day & 9 \\
Selling household assets to buy foods & 13 \\
Moving to other places having more food & 7 \\
Rely on wild foods & 8 \\
Movement to key resource areas & 1 \\
\hline
\end{tabular}

Source: Field survey, 2014

Experiences of reduced rainfall and increase in temperature in the study area have to a great extent reduced crop production. This has affected most farmers' food production systems and changed one of their important means of livelihood [25]. Communities in the studied wards have a various set of approaches they undertake to adapt to changing environmental conditions (Table 3). However, not all approaches are available to all farmers unfortunately nor are the available strategy always successful in buffering food security against variable climate. According to other researchers the central interest is the potential of these measures to offset many of the anticipated negative effects of climate change on food security [26], and in particular the extent to which such adaptations will happen more or less on their own (so called 'autonomous adaptation') as opposed to requiring significant investment and foresight for them to occur ('planned adaptation').

In the study area, growing fast maturing plants scored highest average $(65.2 \%)$ use of pesticide follows (59.2\%), crop rotation $(55.2 \%)$, timing of farming operations also have average of $44.4 \%$ (Table 3 ). These are the major approaches used by the majority of farmers in adapting to climate change. Other strategies like migrating to more green pasture places is not likely and the value identified $(1.2 \%)$ is for young people who move to town centres seeking for jobs. However, issue like selling livestock is also noted (1.8\%).

It was revealed that most people in these wards use these strategies for increasing productivity and not as adaptation measures to the changing climate. This was inline with other 
studies [26, 27] which shows that education/knowledge on climate change and enhancements of adaptation strategies are important to the majority of farmers.

It is important to note that apart from of the impacts of climate change on the study areas, very few respondents $(3.8 \%)$ reported to practice rainwater harvesting. This means that no matter what, water resources are not yet considered to be important in adapting to climate change impacts to local communities. Poor infrastructure and low awareness to majority of farmers might be a factor for poor adaptation to smallholder farmers [24].

Table 3. Percentage Responses on Community Adaptation to Drought Condition.

\begin{tabular}{|c|c|c|c|c|c|c|}
\hline Adaptation mechanism & Nambambo & Ruponda & Lionja & Naipanga & Mbondo & Average \\
\hline Crop rotation & 57 & 42 & 60 & 81 & 36 & 55.2 \\
\hline Growing fast maturing crops & 54 & 66 & 58 & 75 & 73 & 65.2 \\
\hline Buying food & 3 & 8 & 32 & 49 & 57 & 29.8 \\
\hline Emphasis on small stocks & 17 & 28 & 29 & 57 & 44 & 35.0 \\
\hline Timing of farm operations & 42 & 35 & 37 & 30 & 78 & 44.4 \\
\hline Reducing areas cultivated & 12 & 17 & 58 & 8 & 48 & 28.6 \\
\hline Migrating to other places & 1 & 2 & 1 & 0 & 2 & 1.2 \\
\hline Emphasis on livestock keeping instead of crops & 11 & 34 & 7 & 19 & 35 & 21.2 \\
\hline Practicing mixed cropping & 55 & 36 & 67 & 79 & 38 & 55.0 \\
\hline Micro irrigation & 9 & 8 & 12 & 4 & 27 & 12.0 \\
\hline Pest control by using pesticides & 33 & 67 & 78 & 55 & 63 & 59.2 \\
\hline Seasonal migration of pastoralist & 0 & 2 & 5 & 1 & 1 & 1.8 \\
\hline Distributing livestock herds in different places & 12 & 15 & 2 & 24 & 5 & 11.6 \\
\hline Rainwater harvesting & 12 & 6 & 0 & 1 & 0 & 3.8 \\
\hline Agro-forestry & 18 & 4 & 9 & 1 & 4 & 7.2 \\
\hline Selling of livestock & 5 & 1 & 1 & 1 & 1 & 1.8 \\
\hline Planting high yielding varieties & 44 & 14 & 20 & 31 & 41 & 30.0 \\
\hline Simplifying and reducing meals & 2 & 0 & 16 & 20 & 2 & 8.0 \\
\hline Social networking & 4 & 2 & 8 & 22 & 1 & 7.4 \\
\hline
\end{tabular}

Source: Field survey, 2014

Diversified adaptation measures reported could be a reflection that single adaptation approach/strategy cannot be sufficient for communities to be able to adapt to the conditions of climate change/variability. This will need multiple measures to complement each other and to note the local differentiation as some strategies can be applied in specific areas.

Through focus group discussion it was found that households in different socio-economic groups in the study areas undertake different adaptation strategies. For example, it was noted that most of the well-off groups were involved in growing fast maturing crops, cultivation in the wetlands, buying food surplus and rainwater harvesting. This has been due to their possession of financial capital and other livelihood assets as compared to other socioeconomic groups. The poor wealth group, which has limited assets, involved in production of drought tolerant crops, such as sorghum and cassava while the intermediate group is most involved in production of drought tolerant crops and keeping small stocks, as well as seasonal migrations

\section{Conclusion}

The findings of this study have important policy implications for the promotion of climate change adaptation strategies at the farm level in semi-arid regions, coastal area and elsewhere. Farmers in Nachingwea district are confronted with problems of climate variability such as recurrent drought, strong winds and pest infestation. The Tanzanian government is pursuing a policy for sustainable agricultural development in the country. In view of the findings of this study, government should focus on improving the capability and effectiveness of the extension service, which is a catalyst for the promotion of appropriate climate change strategies.

Apart from cost-effectiveness and technical suitability, to labor requirement for adaptation practices, be indigenous or exotic. To facilitate farmer's investment in long-term adaptation options, government should ensure that tenure arrangements, even in communal smallholder farming system in the country, are secured. Similarly, policies that targets women farmers could help them measure to adaptation practices, given the fact that they are heavily involved in the agricultural labor. Out-migration may prevent labor-intensive practices, even if they are indigenous, and farmers are likely to adapt strategies that are relatively less labor intensive, but provide higher returns for the resources involved. Promotion of less labor intensive, but more remunerative strategies would also motivate farmers to apply climate change strategies effectively to plots that are in a relatively good state. Farmer-to-farmer extension also affects adaptation to climate change positively. Policy interventions which encourage informal social networks (materially or financially) can promote group discussions and better information flows and enhance adaptation to climate change.

A major conclusion to be drawn from this research is thus confirmation that adaptation needs to be mainstreamed with development. There is growing recognition of the mutual benefits of linking adaptation with development. On the one hand adaptation is often a low priority in developing countries 
like Tanzania, where developmental needs are more pressing. At the same time there is a risk that development efforts might be undermined by climate change if it is not considered. In order to achieve this, potential development interventions need to be assessed based on whether or not they increase or decrease vulnerability to climate change.

\section{Acknowledgement}

The authors are grateful to all the farmers in Nachingwea districts of (Nambambo, Ruponda, Lionja, Naipanga and Mbondo wards), who kindly spared some of their valuable time for the focus group discussions and questionnaire survey, as well as the officials who participated in key informant interviews. My sincere gratitude appreciation goes my students at Southern Tanzania who worked closely with me and assisted in identifying key informants during data collection.

\section{References}

[1] Waters, T. (2007), The Persistence of Subsistence Agriculture: Life Beneath the Level of the Marketplace, Lanham, MD: Lexington Books.

[2] Aune, J. (2012), Sustainable Agriculture and the Environment: Introduction to Agricultural Systems in Developing Countries, http://tinyurl.com/pe5nsfs Accessed on July 13, 2014.

[3] Miracle, M. P. (1968), Subsistence Agriculture: Analytical Problems and Alternative Concepts, American Journal of Agricultural Economics 292-310.

[4] Cornish, G. A.(1998),Modern Irrigation Technologies for Smallholders in Developing Countries Intermediate Technology, London, UK.

[5] URT (2014), Agriculture Climate Resilience Plan 2014 - 2019, Ministry of Agriculture, Food Security and Cooperatives.

[6] URT (2011a), SAGCOT Investment Blueprint.

[7] URT (2011b), National Strategy on Gender and Climate Change.

[8] URT (2011c), Tanzanaia Agriculture and Food Security Action Plan, 2011-12 to 2020-21.

[9] URT (2011d) Tanzania Agriculture and Food Security Investment Plan (TAFSIP) 2011-12 to 2020 The United Republic of Tanzania.

[10] URT (2010), National Strategy for Growth and Reduction of Poverty - II. Ministry of Finance and Economic Affairs.

[11] FAO, IFAD, WFP (2013), The State of Food Insecurity in the World, The Multiple Dimentions of Food Security, United Nations, Rome.

[12] IPCC (2007), Climate Change: Synthesis Report: The Fourth Assessment Report: The Intergovernmental Panel on Climate Change.

[13] Arndt, C., Farmer, W., Strzepek K. and Thurlow, J. (2011), Climate Change, Agriculture and Food Security in Tanzania. United Nations University - World Institute for Development Economics Research (UNU-WIDER).
[14] Morton, J. F. (2007), The impacts of Climate Change on Smallholder and Subsistence Agriculture, Proc. Natl Acad. Sci. USA104, 19680-19685.

[15] Hertel, T. W. and Rosch, S. D. (2010), Climate Change, Agriculture and Poverty, Policy Research Working Paper 5468. Washington, DC: World Bank.

[16] Coulibaly, Y. J., Kundhlande, G. Amosi, N., Tall A., Kaur H., and Hansen, J. (2015), What Climate Services do Farmers and Pastoralists Need in Tanzania? Baseline Study for the GFCS Adaptation Program in Africa. CCAFS Working Paper no. 110. CGIAR Research Program on Climate Change, Agriculture and Food Security (CCAFS). Copenhagen, Denmark. Available online at: www.ccafs.cgiar.org

[17] Taneja, G., Pal B. D., Joshi P. K., Aggarwal P. K. and Tyagi N. K.. (2014), Farmers' Preferences for Climate-Smart Agriculture: An Assessment in the Indo-Gangetic Plain. International Food Policy Research Institute (IFPRI) Discussion Paper 01337. http://tinyurl.com/odfd7dcAccessed on May, 21st, 2015.

[18] Sakamoto, K. (2003), Social Development, Culture and Participation: Towards Theorizing Endogenous Development in Tanzania; PhD Thesis, Waseda University.

[19] URT (2011e), Strategic Interventions on Priority Irrigation Schemes and Rainfed Crops, Ministry of Agriculture Food Security and Cooperatives, Baseline Study.

[20] Gwambene, B. (2011), Climate Change and Variability Adaptation Strategies: Implication of Adaptation Strategies on Land Resources in Rungwe District, Tanzania. LAP Lambert Academic Publishing, Saarbrucken Deutschland.

[21] Harvey, C. A., Rakotobe, Z. L., Rao, N. S., Dave, R., Razafimahatratra, H., R. Hasinandrianina R., Rajaofara, H. and MacKinnon, J. L. (2015), Extreme Vulnerability of Smallholder Farmers to Agricultural Risks and Climate Change in Madagascar, Phil. Trans. R. Soc. B 369:20130089.

[22] Kangalawe, R.Y.M, Yanda, P.Z. and Sigalla, R.J. (2005). Climatic and Socio-economic Influences on Malaria and Cholera Risks in the Lake Victoria Region of Tanzania, AIACC Working Paper No. 12, available at: http//www.aiaccproject.org

[23] Orindi, V. and Murray, L. (2005), Adapting to Climate Change in East Africa: A Strategic Approach, www.iied.org/pubs/pdf/full/9544IIED.pdf.

[24] Lyimo, J.G. and Kangalawe. R. Y. M. (2010), Vulnerability and Adaptive Strategies to the Impact of Climate Change and Variability: The Case of Rural Households in Semi-arid Tanzania. Environmental Economics 1(2): 89-97.

[25] Kangalawe, R. Y. M. (2012), Food Security and Health in the Southern Highlands of Tanzania: A Multidisciplinary Approach to Evaluate the Impact of Climate Change and other Stress Factors. African Journal of Environmental Science and Technology 6(1), 50-66.

[26] Pardey P. G. and Beintema, N. (2006) Agricultural Research: A Growing Global Divide? IFPRI, Washington, DC.

[27] Pardey, P. G. and Beintema, N. M. (2007), Slow Magic: Agricultural R\&D A Century after Mendel, International Food Policy Research Institute, Washington, DC. 